\title{
Learning at the Edge of History
}

\author{
Justin W. Cook
}

\section{To What End?-Education's Contingent Purpose}

It is clear then that there should be laws laid down about education, and that education itself must be made a public concern. But we must not forget the question of what that education is to be... - Aristotle

\section{To What End?}

To what end do the United States and the European Union together spend approximately USD 1.3 Trillion each year on education? ${ }^{1}$ What return is expected from this investment? What is to be concluded from the fact that the US spends more than USD 600 Billion annually on the nation's public education system while nearly the same sum is spent reforming that very system? Is this an unavoidable symptom of a complex system; or is it indicative of a system not fit for purpose? Does the system even have a purpose? Are the cynics correct in deriding public education as a massive jobs program? Or is it the key to a better future; a platform for addressing humanity's greatest challenges? Is an education system inherent to the contemporary human condition, like healthcare? Or should youths spend their first years doing something else outside of schools? How would society hold that debate and make a choice?

J. W. $\operatorname{Cook}(\bowtie)$

The Finnish Innovation Fund-Sitra, Helsinki, Finland e-mail: jcook@risd.edu

(C) The Author(s) 2019

J. W. Cook (ed.), Sustainability, Human Well-Being, and the Future of Education, https://doi.org/10.1007/978-3-319-78580-6_1 
Let's start with that word: purpose. We are all familiar with the notion of purpose, even perhaps too familiar. Its meaning is why something is done or used; it describes the aim, or intention of an action. Purpose, as it applies to a pencil is clear and virtually unassailable. But purpose as it applies to complex human inventions that continuously evolve beyond the control of any individual or group make purpose a concept difficult to pin down. This is due in part to the fact that these systems continue to operate without regard to whether the actors within the system understand or work toward a larger purpose. However, purpose-in a fundamental sense-is a surprisingly rare focus area in the field of education. Surprising because from an outsider's view, a task as critical and immediate to society's most cherished resource (its children) would seem to require a clearly defined purpose. Yet, a quick review of the education literature reveals purpose to be a marginal topic of research. Most research and thought focuses on practice, authority, learning processes, equity, justice, budgets, etc.-in other words, the mechanics of education. Without question, each of these topics is an area where ongoing research is needed. Teachers must have effective pedagogies. Administrators must find ways to balance authority carefully. Policy makers must be able to assess the system's ability to mitigate social harm among other policy aims. And the system must fundamentally understand how children learn. But to what end? Why is it that society, and even practitioners struggle to discuss purpose coherently with respect to education? To be fair, most agents within complex systems struggle to articulate purpose. But, why hasn't a broad, society-wide debate about perhaps its most pervasive and fundamental activity taken hold especially at this moment when so many of the conditions from which the current education system emerged are irretrievably changed? Why do we focus on reform and not redesign?

Our struggle to answer these questions is due in part to ubiquitous familiarity with the education system. Virtually all of us have encountered formal education at some point in our lives. Even children who are homeschooled are likely using educational resources generated outside the home. According to the 2015 US Census, the average age in the United States is approximately 38 . Nearly $90 \%$ of people aged $35-44$ have a high school diploma or equivalent. Nearly half of those people have an associate's or bachelor's degree (Ryan and Bauman 2016). This means that a significant share of Americans have spent nearly half of their lives in a formal education setting. According to the OECD, "based on 
2012 enrolment patterns, a 5-year-old in an OECD country can expect to participate in education for more than 17 years, on average, before reaching the age of 40" usually followed by additional tertiary education (OECD 2014, p. 306). Other than the home, no other setting will be so familiar. This is especially true for professionals working in the field. According to the OECD, the average age of primary school teachers in OECD countries is 42 (OECD 2013). In the US, these teachers hold a bachelor's degree and $56 \%$ hold advanced degrees (NCES).

Teachers are steeped in education systems; from the age of 4 or 5 , they have been immersed in an educational context. They are perhaps the only profession whose compulsory, secondary and tertiary education environments are the same in which they work professionally. This fact fundamentally challenges the profession's ability to step out of a subjective way of seeing. As George Orwell said, "To see what is in front of one's nose needs a constant struggle" (Orwell et al. 2000, p. 125). This is true for many: because so much of our lives are spent inside schools, education is a relentlessly subjective construct that struggles against the weight of common experience to be seen objectively.

With familiarity comes bias and a lack of critical thought. For much of the population, the purpose of education is self-evident, even though it cannot be clearly articulated. In the United States for instance, public engagement with the public education system seems to spike when attempts are made to change it - to make it unfamiliar. This engagement pattern was experienced most recently with Common Core, and before that, No Child Left Behind, judging by frequency of reporting and parent-stakeholder activism (Murphy 2014). Outside of dramatic policy changes, education systems are treated almost as if they were governed by natural laws; an immutable feature of our contemporary landscape. Purpose need not be questioned when it is so blindingly obvious.

For many people-especially the system's harshest critics-education falls into a category of common sense: we know it to be thus, without knowing why thus is. But common sense is a domain of opinion, unstudied expertise, and strong opinions strongly held. As Paul Saffo insists, strong opinions play an important role in a critical thinking process; strong opinions are a form of intuition built from lived experience and are necessary to confront complexity (Saffo 2008). The problem arises when those strong opinions are also strongly held, meaning that one's viewpoint is not open to change due the emergence of new information or experience. To approach an objective view of education (and thereby 
begin to see its purpose), one must develop strong opinions about education that are weakly held. As Saffo suggests, "strong opinions weakly held is often a useful default perspective to adopt in the face of any issue fraught with high levels of uncertainty" (2008). Given the vastness and complexity of today's education systems, compounded by the uniqueness each educational transaction, uncertainty about its nature and purpose is a fitting descriptor even though we are deeply familiar with its essence. Becoming uncertain about education will require a significant cognitive shift for most people.

We also struggle to answer the "to what end" question because of the monopolizing effect delivery has on teachers and other key actors in education systems. Every weekday morning at public schools around the world, 20 or more students with unique needs, abilities, socioeconomic and cultural backgrounds arrive in a classroom to be taught. What they are taught is a product of many competing agendas, some of which originate outside the core objective of learning. For instance, national cultural assimilation which is happening now across Europe in response to the migrant crisis and which has been a priority as long as formal education has been organized by states. Other learning objectives stem from tradition, political or employment compromises, cutting-edge research and languishing research, etc.; whatever the source, the path dependencies and inertia inherent in curricular and pedagogical approaches are substantial. It goes without saying that triangulation between the inimitability of a student, the capability of a teacher and the legibility of a curriculum is an extremely challenging task-as much art as scienceespecially when under pressure from anxious parents and students. The intensity of this transaction between teacher and student repeated 20 -fold day after day often crowds out any opportunity to step back and not only see, but think critically and strategically about the big picture. Delivery of education "services" is akin to working on an assembly line where tasks relentlessly advance toward the operative. In education, it is hard to aprehend the important when the urgent is totalizing.

It is no wonder that school systems are notoriously difficult to change. Even if a purpose was clear and an objective set, the urgency to deliver will limit the ability of all actors in the system to take steps toward transformation. The organizational hegemony of delivery is not unique to education. Healthcare faces a similar challenge, and the field shares a similarly viscous rate of change. Yet physicians have put in place certain mechanisms that help them step back and look for larger patterns. Morbidity and Mortality (M\&Ms) conferences provide physicians and others 
involved in patient care to review recent complications or errors and update outmoded policies to improve their clinical practice and patient outcomes. M\&Ms help make hospitals learning organizations. They do this by allowing time and space for teams and individuals to reflect on successes and failures while they are removed from the unremitting and urgent pressures of service delivery. These kinds of practices are rare in education; a factor in its diminished sensitivity to questions of purpose.

The questions to what end, and of what purpose is education are not new. Nearly 2400 years ago, Aristotle observed, "it is by no means certain whether training should be directed at things useful in life, or at those conducive to virtue, or at exceptional accomplishments" (Ackrill 1988 , p. 537). He could not answer whether education was to be concerned with a strong intellect or a good life, but he notes that each one of these possibilities has "been judged correct by somebody" (1988), a presage of the endless reform battles to come. With respect to human wellbeing and a future in flux, both objectives of a good life and strong intellect are necessary.

Even the man who many consider the father of modern education, John Dewey wrestled with questions of purpose. At the close of his Kappa Delta Pi lectures in 1938, Dewey prodded his audience with a series of fundamental observations about the nature of education that challenged hasty agreement with his earlier remarks. The education scholar Philip Jackson (2016) reworked Dewey's observations into a series of four questions:

1. What must anything whatever be to be worthy of the name education?

2. What is the nature of education with no qualifying adjectives prefixed?

3. What is education pure and simple?

4. What conditions have to be satisfied so that education may be a reality and not a name or a slogan? (p. 8)

The first three questions can be largely collected under question three, "what is education pure and simple?" where Dewey seems to be driving at the essence of education as a human invention. Why do we have it? What function does it serve in shaping our human condition? This touches on purpose in the sense explored earlier but is perhaps even more fundamental. Question four is closer to asking to what end? When 
education is a reality and not a slogan, it is achieving some desired objective. That means education is no longer a fiction or a strongly held opinion but is working in service of a known purpose. The "conditions" in Dewey's question are both an understanding of purpose, and a mechanism and enterprise that is designed to deliver on that purpose. The "conditions that have to be satisfied so that education may be a reality" is perhaps the best way to begin to think about the future of education.

Yet because education is a human invention and not the result of natural laws as it is often treated, its purpose has always been contingentpurpose has not been an immanent truth in the Hegelian sense. Education's contingent purposes derive from context and ideology, history and the future, democratic compromise and authoritative control. As societies evolve, the purpose for educating evolves. As war breaks out (or some other existential crisis threatens), purpose is sharpened. As stability and affluence return, purpose becomes diluted (Fig. 1.1). Contingency is perhaps education's most enduring trait. Education's purpose is a concept that rides bareback on our species' wild odyssey, hurtling out of the Savannah and into the digital age.

Why is defining purpose so important? Because it flips the debate about education on its head, from one endlessly dominated by argumentative, deductive thinking toward abductive reasoning and experimentation - a shift that reframes how we think about the nature of the challenge and how to achieve a specified outcome. Currently, the most ferociously debated topics about education are process-related. For instance, whether rigorous standards should be set nationally or locally; what subjects should be taught where, when, how or if at all; the utility of high-stakes testing and international rankings; teacher qualifications; the role of technology, etc. These are what and how questions-questions that could be answered when the objective for education was known and relatively straightforward (i.e., inculcation and economic development). But as stated earlier, neither is the purpose of education known today, nor can it be said to be straightforward given the multiplying sources of uncertainty about the future. Deductive thinking in absence of purpose leads to an endless loop of competing narratives about what must be done to fix education. It also creates an ever-shifting landscape of priorities as the preferred outcome of the system can always be defined and redefined locally.

Abductive reasoning can disrupt this loop because it must begin with a clear articulation of a specified outcome, then asks how that objective 


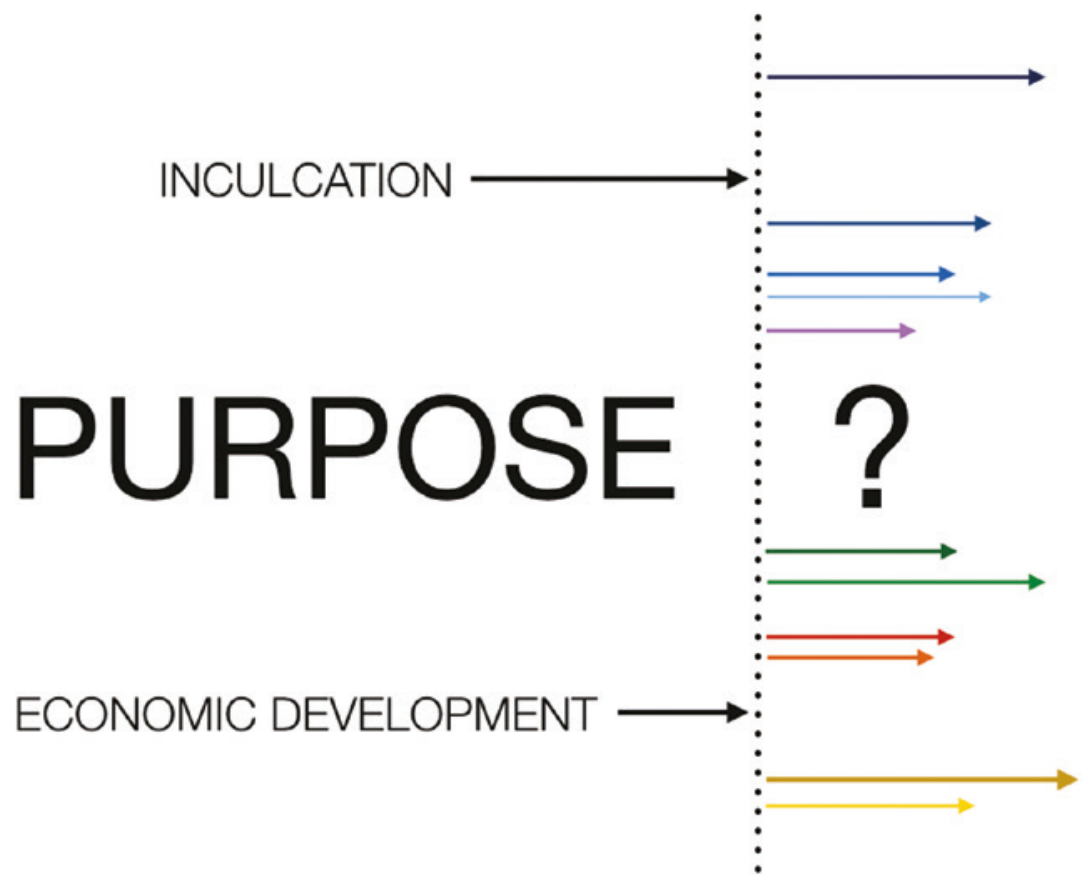

Fig. 1.1 Education's decay of clear purpose in the twenty-first century (by author)

can be achieved. In his book Frame Innovation, Kees Dorst (2015) contrasts "design abduction" (Dorst, 49) with deduction, which he claims to be a traditional, analytical way of thinking that is outmoded by the complex nature of today's wicked problems (of which I would include education). Dorst suggests, "In design abduction, the starting point is that we only know something about the nature of the outcome, the desired value we want to achieve" (49). The task then is to figure out the process questions outlined above. He illustrates this distinction using the reasoning frame What + How $=$ Outcome (45):

Deduction: What + How $=$ ???

Design Abduction: ??? + ??? = Outcome 
In an abductive reasoning process, the outcome must be specified first, agnostic to the means (the what and how). Dorst points out that the means will vary as more is learned about the outcome because of the emergent and adaptive nature of complex challenges like education and thus are fluid. The outcome is held relatively constant, while the means are adjusted to achieve the outcome, even as context and conditions change. This process will ring true to anyone who has set out to catalyze a new or preferred reality. One begins by conceptualizing a new reality (via a vehicle such as a vision statement, manifesto, sketch or diagram) and works to shape conditions toward that reality by various interventions. One generally does not begin this kind of design process by determining what can be done-what reality should be-only after analyzing the existing constraints. Homebuyers for instance, rarely start dreaming about a new home by thinking about budget. The first thoughts that come to mind are location, size and envisioned lifestyle. The means then must be adjusted to achieve that vision, if they can be.

Today, with respect to education and many other core institutions and organizing principles (i.e., democracy), renewing or redefining purpose is critical as the public's confidence in them is slipping away. This is moment of abductive redesign, not incremental improvement. We must have the forthrightness and vision of our forebears who set in motion the construction of these systems and institutions from which we have long benefited but also struggle against today. This necessity for redesign is colliding with the prospect of a radically different future where consciousness itself may no longer be the core competitive advantage of human beings and intelligence has been ceded to machines. Technology, globalized networks and planetary environmental crises are entirely redefining relationships between peoples, between people and the planet and their respective futures. Our newsfeeds are brimming with the indicators of transformation. Our task now is to define what kind of transformation education should undergo, how and to what end.

\section{The Great Transformations}

Something has shifted, it seems. We are making new worlds faster than we can keep track of them, and the pace is unlikely to slow.

-Benjamin H. Bratton 
Much of our contemporary education systems' structure was designed in an era undergoing revolution. Today, the twin revolutionary forces of digitalization and globalization are driving transformation in every domain. But in late nineteenth-century America, widespread industrialization, urbanization and an immigration-fueled population boom following the Civil War were profoundly (re)shaping the country. These demographic and economic shifts combined with a reformist push for literacy and universal human rights (especially labor rights) set in motion the formation of a public education system. Like many things in America, the story is much more complicated because of scale and the diversity of local, state and federal approaches (for instance, Massachusetts made school compulsory already in 1852 while the final state, Mississippi, did not do so until 1917). However, in general, inculcation of national mythos and economic development were top priorities driving formalization of schooling. Ideas held at that time about the purpose of education are hard to state with precision. But I would argue that when the larger elements of the American education system were put in place, the purpose of education would have ostensibly been clearer: Education could help build a nation using the levers of cultural indoctrination of manifest destiny and individualism together with preparation of an industrial labor force. These cornerstones of educationage-based enrollment, subject-based curricula, teacher as authoritative arbiter of knowledge, vocational preparation-persist to today, commonly captured in the "industrial model of education" mantra.

John Gast's 1872 painting American Progress (Fig. 1.2) captures the ferment at the birth of modern America. The allegorical figure Columbia at center shows the way from the light of the East into the darkness of the West. In her left hand, she spools-out telegraph wire, marking the way for the trains that would become the backbone of industry. In front of her flees the collateral damage of nation building (Native Americans and bison). Behind her, the promise of urbanization and mercantilism are softly lit by a rising sun. In her left hand, she cradles a "School Book", indicating the central role public schools will play in realizing the young nation's destiny. Education's purpose could not be more important or manifest to the future of a people: to build a political and economic order where none had existed. Of course, the reality was much more varied than Gast's painting suggests, but the symbolism is nonetheless potent and still informs widely held notions about what the 


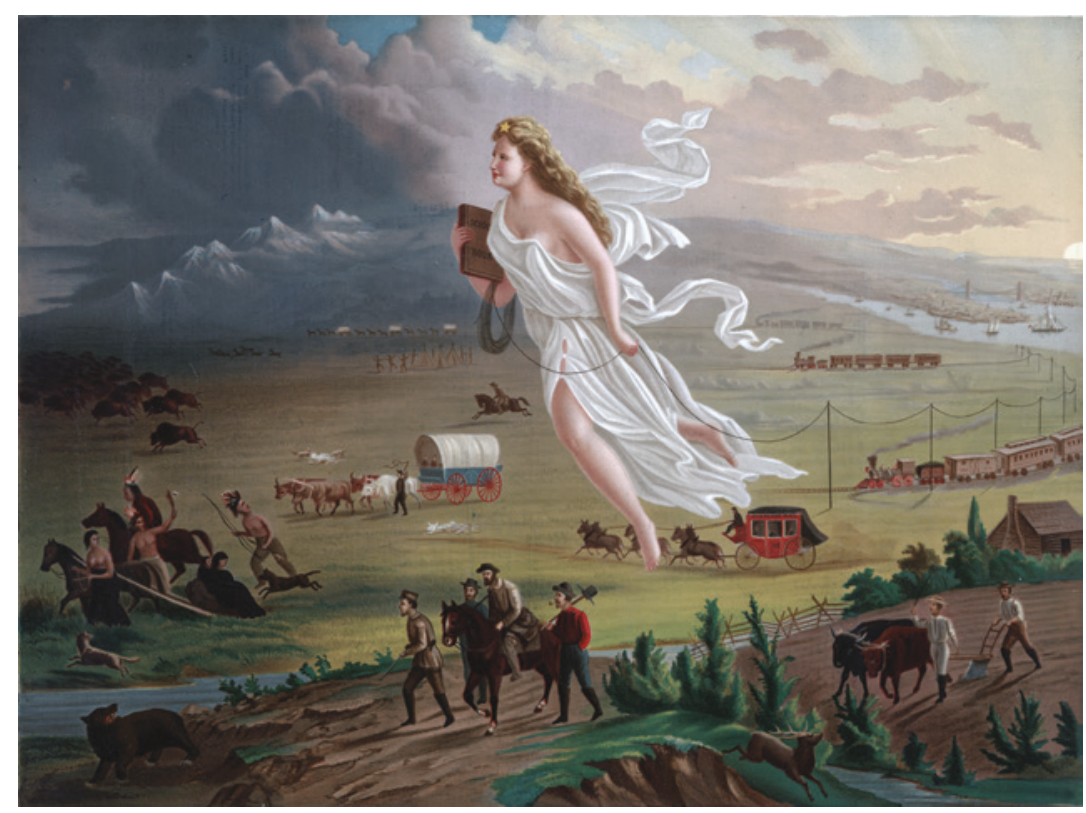

Fig. 1.2 American Progress by John Gast, 1872 (PD-1923)

American education system is intended to do even as the specifics have changed over the last 150 years.

Finland's origin story similarly positions education at (or near) the center of its rapid transformation into an industrialized sovereign nation. Only 100 years ago (1917), Finland declared independence from Russia. At the time, its population of just over 3 million Finns was mostly rural and agrarian, distributed across a large, sparsely populated country. But the population was on the move in search of opportunity in cities. The emerging nation was also in search of a coherent national identity, having been part of the Kingdom of Sweden since the thirteenth century until it was ceded to Russia in 1809. Even after the Second World War, Finland was largely agrarian (Nieminen 2007). The 1950s marked a rapid change from just under half of the country working on farms and $1 / 3$ of the population living in urban areas to today where more than $85 \%$ of the population lives in urban settlements and nearly $3 / 4$ of the population works in service and administrative industries (Statistics Finland). 
This national transformation did not happen in a vacuum-without the influence of public policy. Public education, providing equal access to all, was a cornerstone of Finland's development (and continues to be central today; see Finland's National Curriculum Case Study). Through it would be promulgated the core components of national identity such as shared language and culture. Education would provide the preconditions to an industrialized society such as vocational skills, literacy and a professional class. A strong education system would also vest future generations in the institutions that would construct stable and effective governance structures while fostering the shared ambitions and norms that would enable greater harmony in an increasingly urbanized country. Of course, education did not achieve this alone-many factors were at play. But the national education system was a key instrument of nation building, evidenced by early actions such as the establishment of a Supervisory Board of Education in 1869 and an 1898 decree requiring local authorities to provide all children with schooling. Finland's Constitution enacted two years after independence required compulsory and general education to be provided free of charge (Finnish National Agency for Education) and the education system endures as a source of pride and competitiveness for the nation.

What these illustrations suggest is that education's purpose is most clear during a nation's transformation. That as a country develops, the institutions that shape development have an instrumental role, and thus their purpose is articulated, shared, resourced, and acted upon. But once a country has become developed, and these institutions achieve their transformative mandates, they naturally shift their focus to administrative activities such as maintenance, dispute resolution, incremental change management, and measurement and adaptation. In this administrative environment, organizing principles such as purpose become diffuse and often contradictory across populations as basic needs are largely met and sources of subjective wellbeing become more diverse. Once education is managed as an administrative task, society loses the urgency for renewal and reinvention; the system itself becomes self-sustaining and resistant to significant redefinition.

This administrative state has persisted in the US and Finland (among most other Western countries) for decades, a condition which goes some distance in explaining why public education systems are largely locked in an incremental innovation and reform pattern. In contrast, it is not unusual to encounter education leaders in developing contexts who have 
both a crystal-clear understanding of the purpose and subsequent means of education because for their students, an education is the best-if not only-vehicle to escape poverty. However, in developed nations the need for transformation has emerged again as the orthodoxies of the past seem less and less relevant to the current and future of education as global crises escalate and revolutions in many domains overturn ways of living, working and learning.

\section{Convergence to Common Purpose: Sustainable Wellbeing}

In the face of climate change, everybody is an environmentalist.

- Steward Brand (2009)

Just like the nineteenth century national scenarios outlined above, populations are facing a new existential crisis as the adolescence of the twentyfirst century comes to an end. This time, rather than being an isolated event experienced by embryonic nations, this crisis is common. The disruptive forces of digitalization and globalization together with the rising threat of a climate catastrophe and the push for more sustainable social and economic systems have set in motion what is becoming a global existential crisis - an era linking together the collective fates of all people. Jeffrey Sachs amplifies this view in the opening to Common Wealth: "The defining challenge of the twenty-first century will be to face the reality that humanity shares a common fate on a crowded planet" (Sachs 2008 , p. 3). Why such strong language? The global architecture that has kept global systems stable since the end of World War II is crumbling. Democratic institutions and norms are in retreat in many countries. The spread of liberal internationalism is being slowed by rising populism. Income inequality is at historic levels as employment futures for both blue and white-collar workers are clouded by the rise of technology as a viable alternative to a human labor force. The Holocene climate upon which the human species has staked its twelve millennia of development is showing its destructive alter ego. These are the existential facts of life, true not just for certain segments of the global population, but for everyone. And in response, the faltering systems that have enabled the ascendency of humans are being questioned-in some cases, redesigned.

Sustainability has been the overarching, but vague narrative for how humanity can contend with the conflicts inherent in its extractive and destructive activities, socioeconomic models based on growth and 
the finite nature of planetary resources. Like many far-reaching concepts, sustainability suffers from meaning everything and nothing all at once. Is sustainability Save the Planet sloganeering? Earth Day? School recycling programs? The United Nations Framework Convention on Climate Change? Electric cars? Plant-based diets? Biodegradable utensils? Education for Sustainable Development? Greenwashing? Surely it is all of these things, and more. Hence the challenge of understanding what the concept means. Often, the Brundtland Commission's definition ${ }^{2}$ of sustainable development is cited when introducing sustainability. But this too has limitations. For instance, how can we anticipate the needs of future generations? Certainly, the settlers scratching out an existence on the American plains or tar burners in rural Finland could not anticipate the needs of today's citizenry. Nonetheless, the notion of preserving opportunities for future generations to thrive does provide some direction. And standing by as climate change makes the planet uninhabitable is a clear violation of the Commission's findings.

Of most relevance to this moment three decades later is not the Brundtland definition, but the assertion of our common fate arising from humanity's "interlocking crises" (4) outlined in the Commission's seminal report, Our Common Future. In their telling, the planet is no longer compartmentalized; humanity is bound together by a newly recognized unfragmented reality of our own making whose destructive potential was perhaps understood obliquely only once before during the height of the Cold War. Sustainability, the catch-all, would come to represent a new model-a dramatic shift in direction for society and the planet. Its nature was not known with great precision and its credibility as a true reversal of humanity's most destructive behaviors would have to be tested, but yet this model held the promise of enabling humans to become planetary stewards (Steffen et al. 2011).

In order to advance past Our Common Future, can we be more specific about sustainability? And if so, what does that yield, especially with respect to education? My organization, Sitra-The Finnish Innovation Fund occupies an unusual space in the political, industrial, and academic systems architecture of Finland. Sitra is a public fund with accountability to Parliament, but enjoys independence by virtue of its endowment established by the Bank of Finland in 1967. Its mandate is to improve Finnish society and the economy by providing thought leadership backed by strategic investments that can spur transformation. Since 2012, Sitra has been working to develop an ambitious societal model for the near 
future organized around the theme of sustainable wellbeing. In this distinctly Nordic approach to sustainability, society would build upon the strengths of Nordic social democracy and focus on helping people achieve rich and meaningful lives. This, we believe, is a precondition to spurring a rapid societal transformation toward sustainability; it is when sustainability becomes conflated with sacrifice or austerity that status anxiety and other fears overwhelm an individual's willingness to change behaviors. Nonetheless, in this model, planetary boundaries (Steffen et al. 2015) are the necessary overarching constraint on human activity, while systems of human and social capital aligned with more efficient and human-centered economic and governance models form the building blocks of a sustainable wellbeing society.

As part of Sitra's second working paper on sustainable wellbeing (Hellström et al. 2015), we developed from extensive research six interrelated principles upon which society could establish a new narrative about its future and initiate a transformative cycle of sociotechnical development:

1. Addressing Wellbeing in a Holistic Way: Daily life has become vastly more complex for most people. To cope, better lifemanagement skills and social inclusion are needed; wellbeing must be made a political priority. Personalized solutions that support physical and mental wellbeing while requiring individual responsibility must be prioritized.

2. Adjusting to Planetary Boundaries: Climate change and resource depletion are already acting on societies. The elements of environmental sustainability, such as de-carbonization, must form the basis of policy-making in both public and private sectors.

3. Empowering Individuals and Communities: People must have a voice in the issues that affect them. Citizens must begin to share a vision for a sustainable future and most importantly, be able to find a place to thrive in that future. They must be treated as co-owners, not just customers of policy decisions and community-based solutions should be prioritized.

4. Moving to a Regenerative and Collaborative Economy: Economic structures need to be reformed to foster wellbeing without relying on increasing consumption of natural resources. Businesses should not be treated as if they exist in isolation but are treated as part of an ecosystem. Collaborative and sharing economies point the way forward. 
5. Building Competencies for a Complex World: New competencies will be needed to thrive in a complex, interconnected world where information is ubiquitous. Learning will be lifelong and life-wide. The unique potential of each person is a source of value in an automated world.

6. Developing Inclusive and Adaptive Governance: Governance must evolve both within government and among communities. Administrative silos must be dismantled where necessary in favor holistic, horizontal approaches to policy challenges (Fig. 1.3) (Hellström and Hämäläinen 2015).

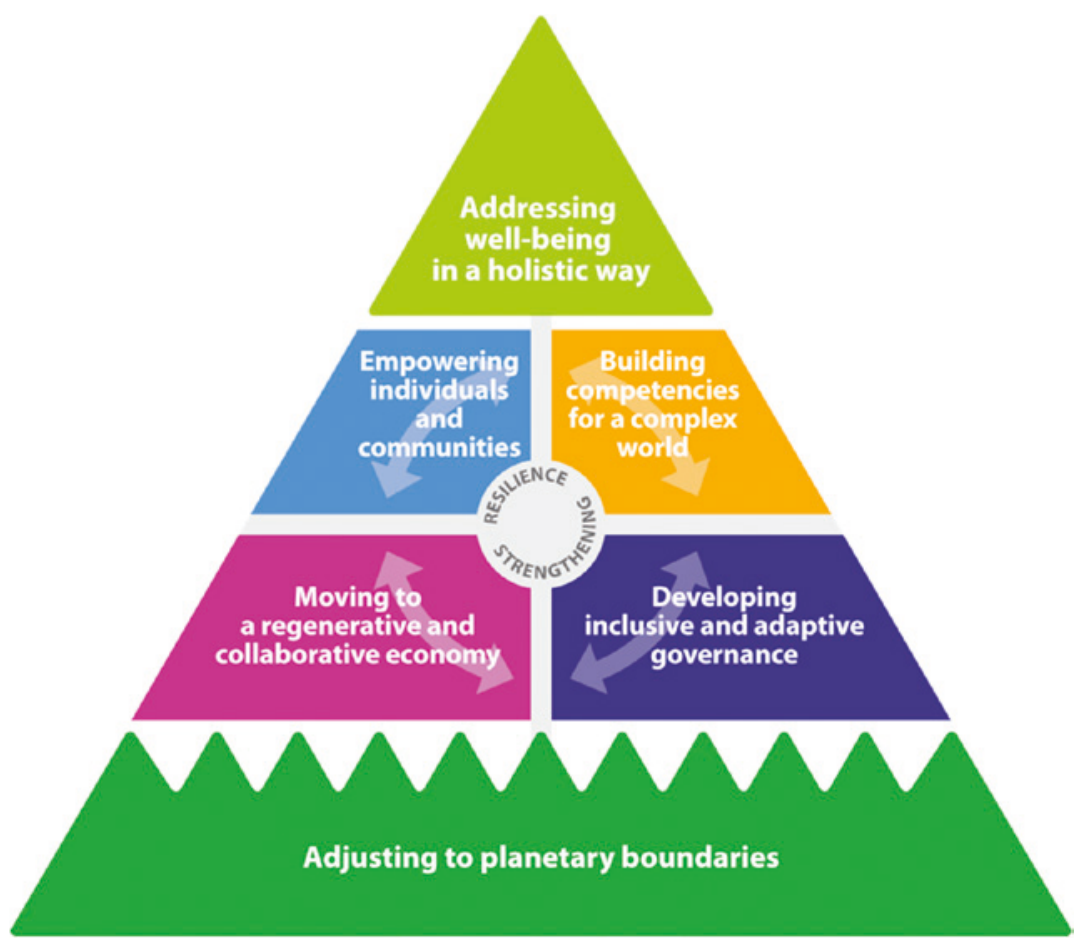

Fig. 1.3 Sitra's Sustainable Wellbeing Model 
These principles aim at propelling Finnish society toward a future where the nation is in balance with the planet, and key systems and institutions are geared to enable human wellbeing. A structural transformation such as this is immensely complex and will touch every sector, organization and governance structure. There will be failures and successes in equal measure. Therefore, sustainable wellbeing research and development will continue to evolve on many fronts by many actors in and outside of Finland. Sitra and its partners are deep in the work of systems change organized under three strategic focus areas: society's capacity for renewal; a carbon neutral, circular economy; and a new working life and sustainable economy. It is expected that the thinking, experiments, investments, coalition building and other efforts conducted under this rubric will together provide a model that can inform the practices of others as they work toward that elusive objective: sustainability.

Sustainable wellbeing is a societal model born out of this singular moment in history where humanity must converge to common purpose in the face of common threats. It is impossible to know if sustainable wellbeing will endure as an organizing principle, but the focused research and experimentation happening globally suggests that this is the moment where sustainability is a concept finally filled with meaning and procedure. This convergence is an opportunity to rethink and redesign many elements of humanity's operating system, not least of which are its systems of learning.

\section{Complexity and Change in Systems of Learning}

Not even revolutions can change schools!

-Jari Salminen

If in this century, humanity will finally come to recognize its common fate-and must therefore converge to common purpose-how will systems of learning need to transform? In what ways will teachers, students, schools, curricula, administrative systems and all of the other mechanics of teaching, learning and organizing undergo transformation, alongside the rest of society? How does a system so complex as education, with an unceasing obligation to deliver and infinite permutations, disrupt its enormous momentum and transform? How will new structures, patterns, and cultures replace old ones? 
It is no secret that schools and especially school systems are hard to change. Dozens of books, articles and opinion pieces are written on how and why to change schools each year. Vast sums of public and private capital are spent on reform toward that end. But as explored earlier, these reform agendas lack an overarching vision for what the purpose of education is to be, especially as humans assume control (and agency) over global systems. Reformers tend to imagine the future as continuous with the past-progression rather than disruption-further entrenching change as a grinding, incremental process; all the while narrowing what is understood to be possible when confronting stagnant education systems. These efforts are also rarely joined-up to leverage individual strengths toward common ends, as one might approach an investment portfolio. And reform is almost always additive, each intervention adding yet another layer of complication onto an already astoundingly complex system.

Within the education field in particular, complexity is a significant barrier to change due to the large number of constituent elements and agents interacting within the system. One simple model tracing accountability for individual schools developed by the OECD (Burns and Köster 2016) identified nearly twenty stakeholder groups that share governance of the school including:

- School Community

Principals, teachers and students

- Governance Community

Training providers, education material providers, private business, parents, communities, local authorities, school boards, school providers, ministry, inspectorate, government agencies, NGOs, labor unions, media, researchers, international organizations, philanthropies, higher education institutions, standardized testing organizations, and related consultancies

To this list can be added the many political figures that claim a stake in education and whom prioritize certain reforms as part of their political agendas. It is also worth recognizing the substantial number of NGOs that can operate in and around schools that have significant influence. Boston Public Schools for instance works with over forty local and national NGOs to provide supplemental services to students, families, teachers, and other professionals working in the system (Pfeiffer 2016). 
The complexity of a school system arises from the vigorous interaction between these elements and the specificities of its particular context resulting in emergence, an axiom of complexity theory. The science journalist M. Mitchell Waldrop (1993, p. 88) described emergence as:

...the agents [elements of a system] were constantly organizing and reorganizing themselves into larger structures through the clash of mutual accommodation and mutual rivalry. Thus, molecules would form cells, neurons would form brains, species would form ecosystems, consumers and corporations would form economies, and so on. At each level, new emergent structures would form and engage in new emergent behaviors. Complexity in other words, was really a science of emergence.

Each arena of interaction between the school community and the governance community, as well as within communities themselves, result in unpredictable behaviors and properties that impact school performance, sustain certain ethos or resist change. Two important implications of emergence are self-sustaining momentum and new independent behaviors that contribute to the evolution or stagnation of a school system. Momentum and independent behaviors can manifest in the resistance to change common in schools, sometimes described as lock-in or the inability to shift away from dominant paradigms. Another implication is that any small, seemingly insignificant element or dynamic within a complex system may in fact be significantly responsible for its behavior. As Mason describes it, "seemingly trivial accidents of history may increase dramatically in significance when their interactions with other apparently minute events combine to produce significant redirections in the course of history, significant shifts in the prevailing balance of power" (Burns and Köster 2016, p. 44).

This last aspect of emergence arising from complexity should undermine confidence in the ability of standardizing administrative systems to effectively be sensitive to what in fact constitutes the system, understand what dynamics are driving behavior and direct school systems toward different outcomes. The efficacy of administrative systems is further limited by the conflict between standardization and contextual variance. As Mason points out, even the trivial (what would commonly arise from contextual peculiarities) can have outsized impact on a system's behavior. Thus, scaling local innovations across systems remains both a pervasive goal and a persistent myth as evidenced by the experiment with charter 
schools in the United States among countless other reform efforts unable to achieve their large-scale, transformative promise. Centralization will always be disadvantaged by emergence.

Mason also points to the dynamic relationship between the number of elements in a system and its complexity, "the successive addition of new elements or agents to a particular system multiplies exponentially the number of connections and potential interactions among those elements or agents, and hence the number of possible outcomes" (44). What this means for schools is that each new reform or intervention by an NGO or political directive for example, layered over the existing operating model, further complicates the system, making it less knowable and less agile. In other words, efforts toward change performed in absence of redesign of the system (or at the very least prioritization of subtractive decisionsdeciding what not to do), only contributes to the school or school system's ability to resist change. Emergence and exponential expansion of interactions inherent in school systems means by definition that administrators have few direct levers of control despite beliefs and expectations to the contrary. Governance of an emergent system is at best improvisational, guided by "practical wisdom" (66). In other words, mechanistic approaches to changing schools are almost guaranteed to have marginal impact. Governance must be adaptive and based on the careful distribution of authority throughout the system to allow for democratized innovation and improvement processes. Of all of the strengths of the Finnish school system, it is perhaps the distribution of authority combined with high level and progressive agenda setting that have made it a structurally sound model. Trust is the key currency that sustains this structure and is often the missing ingredient or pre-condition in other countries hoping to replicate Finland's success.

Stepping back, it is valuable to examine the nature and properties of activity common to education systems and learning more generally, given the role emergence plays in shaping educational systems and therefore outcomes. As suggested earlier in this chapter, each transaction conducted in a school community is essentially unique. Looking only at teacher-to-student instructional interactions for instance, the number of dynamics at play influencing the transaction are myriad: (student) socioeconomic status, nutrition, family history with respect to familiarity and access to education, motivation, confidence, trust, etc.; (teacher) compensation, training, workload, investment in success of the school, tenure, class size, curriculum, testing regime, etc. Each time a lesson is put 
before a learner, or an instruction is provided, or students work together in groups, these underlying conditions-some of which are structural, and others are individual-combine to shape outcomes. Uniqueness is endemic in education systems. While other fields such as medicine have generally found ways to standardize how practitioners interact with the complex, biological human organism, education remains immune to reductionist programs. If anything, education has actually grown in complexity related to the uniqueness of transactions due to the diversification both in inherent and acquired terms of the communities that schools serve. For instance, the rethinking of long-held mental models such as the existence of a "normal" cognitive ability aided by developments such as the neurodiversity movement add additional vectors of uniqueness in educational transactions. Other examples abound from demographic shifts to the atomizing impact of social media and other technologies. Thus, education specifically and learning more generally is beset by non-standard transactions and therefore adaptive behaviors in order to overcome the inability to standardize (emergence). The elements of education interact to generate new behaviors and properties that seem dislocated from what common understanding would say constitutes the education system.

Yet from an administrative point of view, there is an overriding expectation that educational transactions, properly conducted will yield predictable results. And therein lies a central conflict in reform movements (systems change) in education. By not attending to the complexity inherent in education systems, administration writ large is an ineffective framework for governance. Governance must follow from a set of shared principles that emanate from a clear understanding of education's purpose. It demands a whole of system approach that finds "the right combination of mutually reinforcing dynamics" (30) through active experimentation, adaptation, and a bias toward agility and renewal rather than stability and predictability.

But of course, education systems cannot be shut down, redesigned and then restarted as one might an outdated factory; they are critical infrastructure vital to a nation's social fabric. Education systems are heavy, path-dependent systems driven like a flywheel propelled by the momentum of everything that has come before, and fears of what change could bring. And despite their episodic operational tempo, schools are in continuous operation in one way or another (contracts, curricula, legal and statutory obligations, facilities, etc. persist beyond the academic 
calendar). So how can the opportunity for change be created? Given the overwhelming professional reality for teachers and administrators to deliver instruction, manage conflicts, and fill in where other social services fall off-just a few of the many de facto job requirements of educators-how can the conditions be set for transformative change?

There are at least two critical vectors for promoting change in complex systems: first, a restoration, renewal or redefinition of the purpose of the enterprise that constitutes some or all of the system (answering the above question: to what end?); second, creating a space or zone of exemption within or at the margins of the system that enables experimentation and new ways of working, even if they seem to conflict with the norms of the system. In a school system, this zone of exemption could be a classroom or cluster of classrooms, or it could be an entire school within a school district. However, in order for any insights gained to transit beyond the borders of the exemption zone and into the broader system, an organizational learning mechanism must be in place. In terms of organizational architecture, this means that the school or school system must have the means to critically evaluate and learn from its performance. In order to change, schools must become learning institutions, not just institutions of learning.

As discussed briefly above, physicians and hospitals have enabled organizational learning through the practice of Morbidity and Mortality (M\&Ms) conferences. M\&Ms provide the machinery to manage and adapt to the complexity and emergence inherent in healthcare. Similar learning paradigms exist in other industries. The aviation industry for instance, would today be beset by passenger jet crashes had the federal government not developed a rigorous forensic engineering regime activated after each accident large and small. The National Transportation Safety Board (NTSB) has primary authority to investigate accidents by deploying "go teams" composed of different kinds of experts working in concert with representatives from industry to develop a holistic understanding of what happened and why and to make recommendations that inform everything from engineering specifications to pre-flight safety briefings. The NTSB is a prime example of organizational learning operating at scale across a diverse, fragmented industry.

Why is there not an analog of the NTSB for education? Funding priorities is an obvious first answer. However, the question reveals a fundamental error in the original "design" of most education systems: they were devised to convey stable bodies of knowledge to average pupils. 
Education systems were not designed to cope with the complexity inherent in the enterprise of teaching and learning or the pace of exponential change in the twenty-first century. It is worth highlighting that the concept of average that shapes so many of our modern systems and institutions (in healthcare, the Body Mass Index or blood pressure; in social policy, the average income of certain classes of workers; in higher education, admissions based on standardized test performance relative to an average) is not a natural law but a revolutionary invention of the eighteenth century. Adolphe Quetelet, the astronomer turned author of average "declared that the individual person was synonymous with error, while the average person represented the true human being" (Rose 2016), setting in motion the reconceptualization of the human according to standardizing logics derivable from data. There are encouraging trends however in some schools and districts to reorient instruction around the individual learner rather than the average emanating from larger societal changes such as the neurodiversity movement and practice level support from important books such as Schools for All Kinds of Minds. This broader shift toward personalization enabled largely by technology still has far to go to determine its real potential, but the impact on medicine, education, and other domains could be profound.

An effective example of how to create a space for change in a conflicted system is the work of Creativity Culture and Education (CCE). CCE is an international foundation based in Newcastle UK that has worked with over a million students and tens of thousands of teachers around the world to help them regain the possibility of creativity in teaching and learning despite a system some say is designed to kill it. CCE's approach utilizes carefully designed interventions that aim to create a platform for new possibilities, dialog and language in traditional, struggling school systems. The basic model is to partner creative practitioners (called Creative Agents) such as artists and designers with teachers and students to design shared cultural activities related to classroom subjects. Creative Agents are key because they lack the constraints teachers and administrators must navigate and tend to focus on process rather than outcome: where teachers will adhere to a standard for "what", Creative Agents adhere to a standard for "how". For instance, a project in a math class lead by a Creative Agent might be intended to de-siloize math from its often isolated and isolating experience. Through a seemingly tangential project co-led by the Agent and teacher, math would 
become entangled in the world in students' minds; part of a larger narrative rather than a discrete subject.

In order to establish the enabling conditions, CCE coordinates with at least seven layers of governance in advance of the intervention: government, arts councils, schools, headteachers/principals, teachers, students, and parents. In the process, both students and teachers engage a new, exploratory language of creativity, challenge traditional roles and hierarchies and thereby, open the opportunity to explore fundamental questions of community, learning and motivation. This focus on creative language leverages research that suggests poor students especially are mainly exposed to administrative forms of language and have limited access to exploratory language critical to creativity. Within this space of critical reflection, the CCE process enables dialogue around the purpose of education to rise to the surface, offering even the most static learning environments an opportunity to discuss alternative futures and ways of working. And students are shown tools that enable their agency and therefore help unlock their creativity. This process of intervention, reflection and redirection is critical helping school systems escape the inertia of their pasts and open zones of experimentation and change. Follow-up analysis has shown math and literacy improvement as well as improvements in attendance following CCE's interventions. ${ }^{3}$

If the second vector of change (zone of exemption) is to become transformative, in addition to requiring the feedback loops available to a learning organization, the change process will require a sustaining architecture that can span the significant time scales necessary to overcome structural challenges such as school culture or instructional practices. This architecture must also be able to attend to as many of the stakeholder groups listed above as possible. Writing for the OECD, Mason (2014) argues, "change and sustainable development in education, at whatever level, are not so much a consequence of effecting change in one particular factor or variable, no matter how powerful the influence of that factor. It is more a case of generating momentum in a new direction by attention, as I have argued, to as many factors as possible" (p. 6). This means that transformative change cannot be a marginal activity. Change requires the convergence of many dynamics. The complexity of schools and school systems obliges a substantial investment in redesign (inducement) to keep open the spaces where alternate futures can be glimpsed and struggled toward. In a highly resource constrained environment 
such as a school, this investment is likely out of reach. So, what can be done? For this question, there are no easy answers.

However, part of the answer lies in the mindset of those seeking change. Thinking in terms of systems is the first step. Systems design, while possibly feeling overwhelming to already overburdened teachers and administrators, can be made accessible by showing the extent to which these communities already act as systems designers out of necessity. If design is fundamentally about taking actions to realize change one wants to see in the world, educators are certainly qualified. Next is to familiarize these educators-come-designers to frame challenges in terms of systems problems and to shape decision-making according to systemlevel dynamics rather than object or issue level problems. How? By following the decades-old advice of Finnish architect Eliel Saarinen when developing one's praxis:

Always design a thing by considering it in its next larger contexta chair in the room,

a room in a house,

a house in an environment, an environment in a city plan.

By democratizing the ability of stakeholders in educational systems to work toward alternate futures, the critical mass necessary for systems change can be reached; attention can be paid to as many factors as possible. A systems design capability will provide educators agency in realizing a better future.

\section{LEARNING FOR THE Frontier}

At the edge of history the future is blowing wildly in our faces, sometimes brightening the air and sometimes blinding us.

—William Irwin Thompson (1979)

A prosperous future can only be one that has been transformed by humanity coming to terms with its common fate. It is a future of interconnectedness, diversity, complexity, disintermediation, and fluidity. The taxonomies of isolation and reduction will be knitted back together into a holistic understanding of ecosystems and planetary systems, 
reinvigoration of the humanities as both theory and praxis participating in those systems, and redefinition of fundamental organizing principles of modernity such as value and average. This is no less a significant shift than that underway since the Enlightenment. But this history is rapidly retreating in the rear view and the world is becoming governed by a new set of rules, most of which are not yet known.

Yet humanity has been here before-for much of its existence in fact. This condition still captures the imagination of Americans and informs their character 150 years after "the west was won". It enchants Finns as they retreat to nature during summer rituals. It is the state of living on a frontier.

Learning at the edge of history means that humanity is now learning for the frontier. At this extreme limit of known territory, of known knowns as Donald Rumsfeld would have it, the objective and act of learning and the purpose of education must be redefined and continually renewed. It means that even with the massive increase in the stock of human knowledge, the unknown now may outweigh what is known. How could that be possible? Because what is known now must be reexamined in relational terms. The intellectual efficiencies gained by eliminating contingencies such as "externalities" in economics, cannot be sustained in an interconnected, common era. Humanity must now learn to navigate the expanding white spaces between known knowns.

For the enterprise of education, this means that the division of phenomena into subjects represents a fundamentally flawed way to understand the world. It means that real world connection must be established to classrooms and curriculum in order to ensure education systems are not outmoded by a rapidly evolving global landscape and that learners understand their agency in realizing alternate futures. The objective of learning, therefore must be to restore human agency (an idea akin to Carol Dweck's growth mindset). Theory and practice must be joined together; MIT's motto Mens et Manus (mind and hand) is more relevant and applicable than ever. Diversity of ability, ideas and beliefs will be the only way to reliably navigate the frontier of the unknown.

Technology will undoubtedly give students an unprecedented, multidimensional space of options, opportunities and even realities. Tech will continue to drive change at a pace unimaginable in the confines of human institutions. Can current and future generations retain control over technology? The scientist Danny Hillis (2016) suggests that: 
As our technological and institutional creations have become more complex, our relationship to them has changed. We now relate to them as we once related to nature. Instead of being masters of our creations, we have learned to bargain with them, cajoling and guiding them in the general direction of our goals. We have built our own jungle, and it has a life of its own.

Perhaps then the objective of learning with respect to technology is not so much control as it is to define its effect while navigating the ways it changes fundamental relationships and definitions. This fluidity between what is certain and what is new is endemic to the frontier, to Hillis' "jungle".

In a 2017 event at the OECD in Paris, the relatively newly appointed head of the Finnish National Agency for Education Olli-Pekka Heinonen claimed in effect that the Enlightenment project of certainty had come to an end. That the task now is for societies and institutions to embrace uncertainty as an organizing principle of this era which will demand that humanity question how fundamental assumptions have been constructed and how knowledge has been organized. While this may seem unnerving, perhaps even frightening, it is also an opportunity no less exhilarating and full of potential than what René Descartes must have viewed as he peered into the brightened air of the future. It can also be made very simple. In the documentary film Look \& See (2016), its subject Wendell Berry observes that we live in an age of divorce where "things that belong together have been taken apart". In order restore the connection between things and to make progress, "you take two things that ought to be together, and you put them back together. Two things, not all things". Our task in his view is to convert parts into wholes.

For students and (lifelong) learners more generally, the opportunity now is to not just be subject to the future, but to be complicit in its formation. At the edge of history, nothing is given, everything is frontier.

\section{Notes}

1. US: USD 620 Billion, 2011-12 (https://nces.ed.gov/fastfacts/display. asp?id=66); EU-28: EUR 672 Billion, 2012 (http://ec.europa.eu/eurostat/ statistics-explained/index.php/Educational_expenditure_statistics).

2. Sustainable development is development that meets the needs of the present without compromising the ability of future generations to meet their own needs.

3. https://www.creativitycultureeducation.org/research/. 


\section{REFERENCES}

Ackrill, J. L. (1988). A New Aristotle Reader. Princeton: Princeton University Press.

Brand, S. (2009). Whole Earth Discipline: An Ecopragmatist Manifesto. New York: Viking.

Burns, T., \& Köster, F. (Eds.). (2016). Governing Education in a Complex World, Educational Research and Innovation. Paris: OECD Publishing.

Dorst, K. (2015). Frame Innovation: Creating New Thinking by Design. Cambridge, MA: The MIT Press.

Dunn, L., \& Sewell, J. (Directors). (2016). Look \& See: A Portrait of Wendell Berry [Motion picture on DVD]. United States: Two Birds Film.

Finnish National Agency for Education: Educational Provision. (n.d.). Retrieved February 13, 2017, from http://www.oph.fi/english/education_system/ historical_overview/educational_provision.

Hellström, E., \& Hämäläinen, T. (2015, May). Towards a Sustainable Well-Being Society. Retrieved January 15, 2017, from https://www.sitra.fi/en/news/ towards-sustainable-well-being-society/.

Hellström, E., Hämäläinen, T., Lahti, V., Cook, J. W., \& Jousilahti, J. (2015). Towards a Sustainable Well-Being Society: From Principles to Applications (Sitra Working Papers). https://media.sitra.fi/2017/02/23221124/Towards_a_ Sustainable_Wellbeing_Society_2.pdf.

Hillis, D. (2016, February 23). The Enlightenment Is Dead, Long Live the Entanglement. Retrieved February 22, 2017, from https://jods.mitpress.mit. $\mathrm{edu} / \mathrm{pub} /$ enlightenment-to-entanglement?panel=collaborators.

Jackson, P. W. (2016). What Is Education? Chicago: The University of Chicago Press.

Mason, M. (2014). Complexity Theory in Education Governance: Initiating and Sustaining Systemic Change. Lecture presented at "Understanding Complexity: The Future of Education Governance" Oslo, 10.

Murphy, T. (2014, September). Inside the Mammoth Backlash to Common Core. Retrieved March 18, 2017, from http://www.motherjones.com/ politics/2014/09/common-core-education-reform-backlash-obamacare.

NCES. (n.d.). NCES Fast Facts: Teacher Trends. Retrieved March 5, 2017, from https://nces.ed.gov/fastfacts/display.asp?id=28.

Nieminen, M. (2007, December 5). Population Development in Independent Finland-Greying Baby Boomers. Retrieved April 20, 2017, from http:// www.stat.fi/tup/suomi90/joulukuu_en.html.

OECD. (2013). Education at a Glance 2013: OECD Indicators. Paris: OECD Publishing.

OECD. (2014). Education at a Glance 2014: OECD Indicators. OECD Publishing. https://doi.org/10.1787/eag-2014-en. 
Orwell, G., Angus, I., \& Orwell, S. (2000). In Front of Your Nose: 1946-1950 (Vol. 4). Boston: Godine.

Pfeiffer, S. (2016, July 4). Does Boston Have Too Many Nonprofits? Some Say Yes-The Boston Globe. Retrieved January 20, 2017, from https://www.bostonglobe.com/business/2016/07/04/does-boston-have-too-many-nonprofits-some-say-yes/XMnV259wjXdugZqrOl3CvI/story.html.

Rose, T. (2016, February 18). How the Idea of a 'Normal' Person Got Invented. Retrieved January 22, 2017, from https://www.theatlantic.com/business/ archive/2016/02/the-invention-of-the-normal-person/463365/.

Ryan, C. L., \& Bauman, K. (2016, March). Educational Attainment in the United States: 2015 [PDF]. Washington, DC: United States Census Bureau. https://www.census.gov/content/dam/Census/library/publications/2016/ demo/p20-578.pdf.

Sachs, J. D. (2008). Common Wealth: Economics for a Crowded Planet. New York: The Penguin Press.

Saffo, P. (2008, July 26). Strong Opinions Weakly Held. Retrieved March 19, 2017, from http://www.saffo.com/02008/07/26/strong-opinions-weakly-held/.

Statistics Finland. (n.d.). Finland Then and Now: Century Comparisons. Retrieved May 1, 2017, from http://www.stat.fi/ajk/satavuotiassuomi/ suomiennenjanyt/vuosisadanvertailut_en.html.

Steffen, W., Persson, Å., Deutsch, L., Zalasiewicz, J., Williams, M., Richardson, K., et al. (2011). The Anthropocene: From Global Change to Planetary Stewardship. Ambio, 40(7), 739-761. http://doi.org/10.1007/s13280-011-0185-x.

Steffen, W., Richardson, K., Rockstrom, J., Cornell, S. E., Fetzer, I., Bennett, E. M., et al. (2015). Planetary Boundaries: Guiding Human Development on a Changing Planet. Science, 347(6223), 1259855-1259855. https://doi. org/10.1126/science.1259855.

Thompson, W. I. (1979). At the Edge of History. New York: Harper and Row.

Waldrop, M. (1993). Complexity: The Emerging Science at the Edge of Order and Chaos. London: Viking. 
Open Access This chapter is licensed under the terms of the Creative Commons Attribution 4.0 International License (http://creativecommons.org/licenses/ by $/ 4.0 /)$, which permits use, sharing, adaptation, distribution and reproduction in any medium or format, as long as you give appropriate credit to the original author(s) and the source, provide a link to the Creative Commons license and indicate if changes were made.

The images or other third party material in this chapter are included in the chapter's Creative Commons license, unless indicated otherwise in a credit line to the material. If material is not included in the chapter's Creative Commons license and your intended use is not permitted by statutory regulation or exceeds the permitted use, you will need to obtain permission directly from the copyright holder.

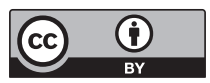

